\title{
Editorial
}

Flaviana Miranda da Silva de Sá ${ }^{1}$

Euclides Reuter de Oliveira ${ }^{2}$

Veronica Aparecida Pereira ${ }^{3}$

Temos a honra de entregar a Comunidade Universitária o Volume 7, Número 14 da RealizAção - Revista Online de Extensão e Cultura com o objetivo de tornar públicos os artigos avaliados e tendo como tema a multidisciplinaridade, com a intenção de discutir questões de interesse comum, além de aprimorar a divulgação das diversas experiências realizadas pelos extensionistas.

Olhar para o presente em cada região do Brasil é ver o futuro do planeta e enxergar recortes que visem melhorar a qualidade de vida, sustentabilidade e minimizar impactos ambientais. Nesse pensamento, a Revista RealizAção conta com a contribuição de autores de diferentes regiões do Brasil, como Bahia, Mato Grosso do Sul, Minas Gerais, e Rio Grande do Sul. Os artigos apresentados estão divididos nos seguintes temas: 1- Meio Ambiente; 2- Tecnologia de Produção; 3- Trabalho; 4- Saúde; 5- Educação; e 6- Direitos Humanos e Justiça.

\section{MEIO AMBIENTE}

O artigo "Sensibilização ambiental de estudantes de uma Escola Estadual no Noroeste do Rio Grande do Sul", promoveu a sensibilização ambiental, com ênfase no gerenciamento dos resíduos sólidos, com estudantes da Escola Estadual de Ensino Fundamental Gonçalves Dias em Três Passos/RS. O trabalho foi desenvolvido na referida escola com 15 alunos do $5^{\circ}$ ano. A primeira etapa do estudo consistiu na observação visual das condições momentâneas da separação dos resíduos sólidos na escola e determinação da massa dos mesmos. Após, realizou-se a aplicação de um questionário avaliando o conhecimento dos participantes do projeto sobre a reciclagem. Posteriormente procedeu-se a sensibilização ambiental através de palestras, oficinas pedagógicas, vídeos e jogos didáticos e, por fim, fez-se nova avaliação dos temas para atestar a efetividade da sensibilização.

1 Administradora da PROEX e Editora da Revista Realização.

2 Docente na Faculdade de Ciências Agrárias -FCA/UFGD

3 Docente na Faculdade de Ciências Humanas - FCH/UFGD. 


\section{TECNOLOGIA DE PRODUÇÃO}

O artigo "Jams produced by family agribusiness: Diversification strategies to improve process", consistiu em contribuir com o fornecimento de geleias com reduzido valor energético, permitindo incrementar as contribuições da agricultura familiar no cenário socioeconômico de sua atuação. Para isto, a geleia de Dona Izaltina (GdI) foi analisada quanto a atividade de água, umidade, sólidos solúveis, acidez e pH. Para propor uma geleia menos doce, foi elaborado o produto com polpa de guavira, sacarose, glicose e pectina cítrica. Simultaneamente, realizou-se uma avaliação sensorial com julgadores treinados, com o intuito de fornecer subsídios para melhoria sensorial da geleia.

$\mathrm{O}$ artigo intitulado de "Assistência técnica e gerencial e a extensão rural por meio da ferramenta ISA: um estudo de caso no Sítio Nazareth - Ipanema-MG", avaliou a sustentabilidade do Sítio Nazareth, por meio da análise dos Indicadores de Sustentabilidade do Agroecossistema (ISA) e propôs-se um plano de adequação. A ferramenta ISA propiciou ótimo roteiro e gerou dados de forma eficiente e eficaz para a promoção de ATER. É importante que o plano de adequação seja colocado em prática e as oportunidades exploradas, de forma a elevar a eficiência da atividade produtiva e garantir a sustentabilidade do agroecossistema.

$\mathrm{O}$ artigo "Profile of caipira broiler meat producers and consumers in the Alto San Francisco Region - MG", teve como objetivo avaliar o perfil dos produtores e consumidores de frangos tipo caipira da Região do Alto São Francisco - MG. A pesquisa foi realizada no município de Bambuí - MG, situado no centro oeste mineiro. A produção e o consumo de carne de frango tem crescido muito durante os últimos anos. Com isso os consumidores e os produtores de frango passaram a se preocupar mais com cada processo produtivo da cadeia avícola, visando assim um produto final de boa qualidade.

\section{TRABALHO}

$\mathrm{O}$ artigo " Importance of program for integrating at university into the field proin for undergraduates in zootechnics of the state university of Montes Claros", teve como objetivo realizar uma análise sobre as atividades do Programa de Integração 
da Universidade ao Campo - PROIN, da Universidade Estadual de Montes Claros, Campus de Janaúba, situada no Norte de Minas Gerais, quanto às visitas feitas pelos alunos de Zootecnia de forma estratégica visando integrar o universitário à realidade rural, permitindo o aprimoramento técnico acerca das atividades práticas da graduação.

\section{SAÚDE}

O "Relato de experiência: roda de tereré para adolescentes na Unidade Básica de Saúde (UBS) - Vila Vieira", este relato teve por objetivo discorrer sobre a intervenção executada na UBS Vila Vieira da cidade de Dourados - MS, que se consistiu em uma roda de conversa direcionada para jovens da região com a intenção de abordar temas do cotidiano dessa faixa etária, como saúde emocional, sexualidade e doenças sexualmente transmissíveis. Tal ação teve como foco principal sanar as dúvidas concernentes às temáticas citadas, a fim de informar e contribuir para a promoção de saúde dessa faixa etária.

\section{$\mathrm{O}$ artigo "Desenvolvimento de atividade entre alunos e animais de} companhia resgatados", teve por objetivo relatar uma atividade desenvolvida com os cães da Associação de Resgate e Cuidado Animal - ARCA em Janaúba-MG por alunos do curso de Zootecnia da Universidade Estadual de Montes Claros (UNIMONTES), visando proporcionar melhor bem-estar dos animais resgatados. As atividades desenvolvidas entre os acadêmicos e os animais resgatados proporcionaram melhoria no bem-estar físico e emocional dos cães do abrigo, bem como despertou atitudes de compaixão, respeito, senso de responsabilidade e dever nos alunos para com os animais abandonados.

$\mathrm{O}$ artigo "Promoção da saúde sexual e reprodutiva de mulheres na perspectiva de gênero: uma ação extensionista", teve por objetivo relatar vivências de promoção da saúde sexual e reprodutiva com mulheres participantes do projeto extensionista "Mulheres em ação pela saúde e cidadania", do curso de Enfermagem da Universidade Regional Integrada do Alto Uruguai e das Missões, Campus de Santiago, RS. A promoção da saúde sexual e reprodutiva de mulheres pode ser enriquecida pelas ações de educação em saúde na perspectiva de gênero, tendo em vista que este enfoque possibilita visualizar o sujeito além das diferenças sexuais. 


\section{EDUCAÇÃO}

No artigo "Do diálogo à experiência extensionista nos territórios do Sisal e Piemonte Norte do Itapicuru pela FETRAF - BA ", o objetivo foi relatar a vivência nas comunidades e propriedades rurais nos municípios de Senhor do Bonfim, Pindobaçu, Ponto Novo e Monte Santo, com foco em diferentes áreas da produção rural, abordando desde o acompanhamento efetivo de assistência técnica para agricultura, pecuária, nas melhorias ambientais e o empreendedorismo, até o processo de organização e efetivações de atividades sociais nas comunidades. As atividades desenvolvidas propiciaram o entendimento da dinâmica de trabalho de uma organização voltada para ações de extensão. Assim, de forma conjunta, foi possível compreender as formas de abordagem e sistematização das ideias por parte dos técnicos da FETRAF-BA nas comunidades.

\section{DIREITOS HUMANOS E JUSTIÇA.}

Este relato de experiência "Comércio de dentes humanos - ações para combater essa prática ilegal", tem como objetivo demonstrar ações extensionistas voltadas para o combate ao comércio ilegal de dentes através de visitas aos cemitérios da cidade com o intuito de promover conscientização dos coveiros acerca dos preceitos éticos, legais e biológicos que envolvem o comércio de dentes.

Assim, ao entregarmos esta edição da Realização com essa ampla diversidade de artigo, especialmente voltada às questõe de saúde e tecnologia de produção, esperamos promover novas discussões, além de fomentar o desenvolvimento de outras ações de extensão voltadas para essas áreas. 